Document downloaded from:

http://hdl.handle.net/10251/50097

This paper must be cited as:

Molina Morales, FX.; Expósito Langa, M. (2013). Overcoming undesirable knowledge redundancy in territorial clusters. Industry and Innovation. 20(8):739-758.

doi:10.1080/13662716.2013.856622.

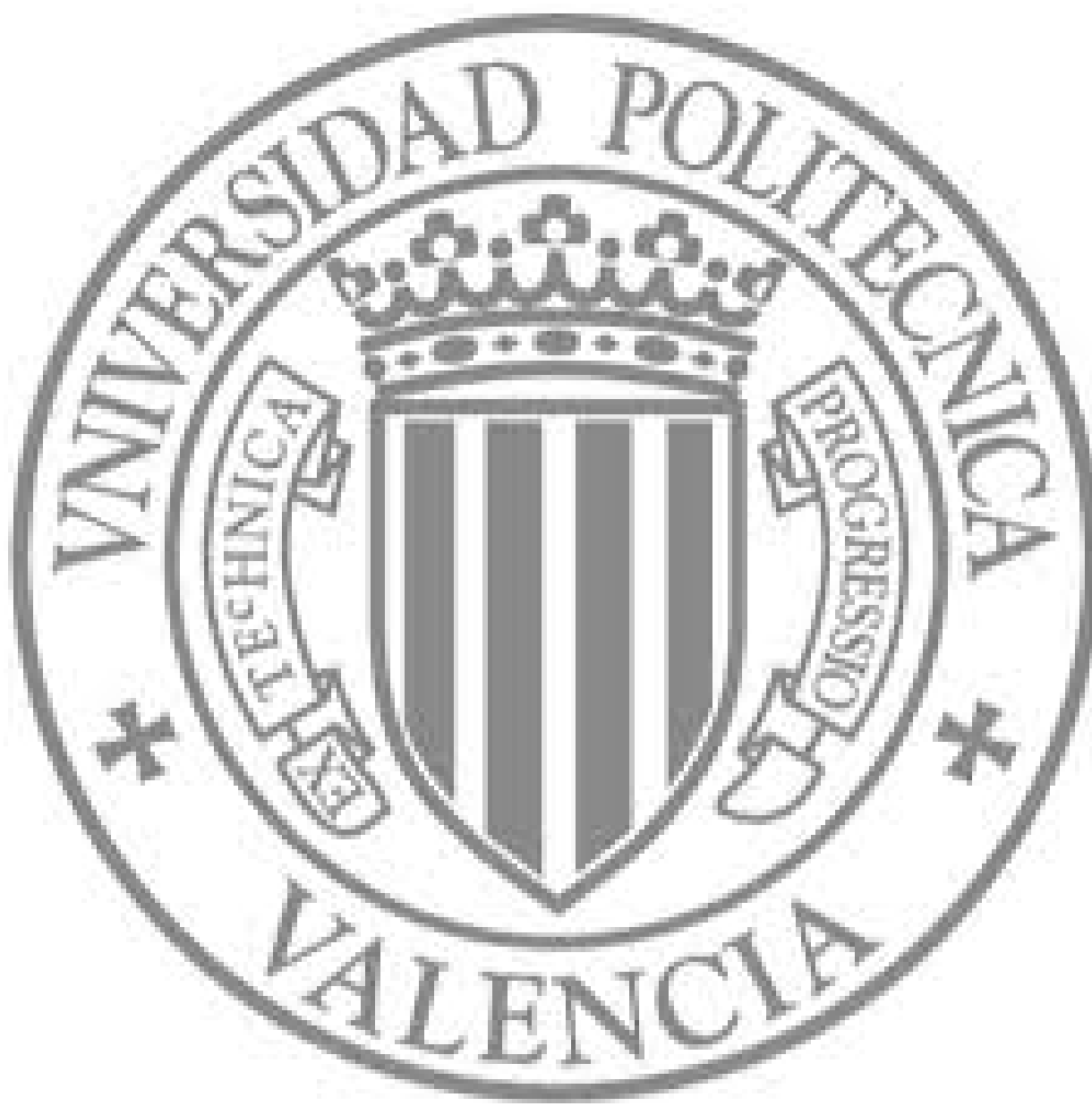

The final publication is available at

http://dx.doi.org/10.1080/13662716.2013.856622

Copyright Taylor \& Francis (Routledge): SSH Titles 


\title{
OVERCOMING UNDESIRABLE KNOWLEDGE REDUNDANCY IN TERRITORIAL CLUSTERS
}

\author{
F. Xavier Molina-Morales \\ Universitat Jaume I \\ Department of Business Administration \& Marketing \\ Campus Riu Sec, 12080 Castellón (Spain) \\ molina@emp.uji.es \\ Manuel Expósito-Langa \\ Universitat Politècnica de València \\ Business Administration Department
}

Plaça Ferrandiz i Carbonell 2, 03801. Alcoi (Alacant), Spain

maexlan@doe.upv.es 


\section{OVERCOMING UNDESIRABLE KNOWLEDGE REDUNDANCY IN TERRITORIAL CLUSTERS}

This work analyzes the existence of redundant knowledge associated to geographic networks of firms. Specifically, our research focuses on how firms can avoid inefficient redundancy ties derived from territorial clusters. We propose that firms embedded in a dense and strong-tie network generate redundant knowledge flows. However, they may use structural dispersion to mediate and overcome this limitation. Our empirical study was conducted drawing on the Spanish ceramic tile industrial cluster to test the potential association between social capital and redundancy. Our findings support the idea that structural dispersion mediates the effects of strong ties and the generation of knowledge redundancy.

Keywords: ceramic tile, cluster, social capital, knowledge, network

\section{INTRODUCTION}

Over the last few decades, contexts of geographical proximity, such as those defined as industrial clusters, have received a lot of attention (Porter, 1998; Tallman et al., 2004). Particularly, industrial clusters can be viewed as networks within a production context inside a geographically defined area where many different actors are involved. These may include final product firms, suppliers, customers, service providers, local institutions, policy agents, and so on (Boschma and Ter Wal, 2007; Parrilli and Sacchetti, 2008). In general, a cluster may be identified as a category of a dense strongtie network with intense, frequent, and close relationships between members (Trigilia, 2001). The network perspective has contributed to a better understanding of knowledge and innovative processes in geographical clusters (Giuliani and Bell, 2005; Boschma and Ter Wal, 2007). Social networks undoubtedly have a territorial dimension (Staber, 2001; Lorenzen, 2007), and in this respect the informal ties that are produced naturally 
between close actors are particularly relevant (Malecki, 1995). Also, territorial clusters (Porter, 1990; Becattini, 1990) have been represented through the network metaphor in order to map and visualize both the actors involved and the interactions that take place among them (Boschma and Ter Val, 2007; Parrilli and Sacchetti, 2008).

The industry cluster is considered to be a particular case of networked organizations (Sorenson, 2003). Whereas firms within networks might be spatially dispersed, an industry cluster is characterized by geographical proximity and the concentration of firms and other participant organizations in a location. In contrast, relational closeness, which occurs more often in networks, implies the interconnections and interactions between behavioral actors in the network. Geographical proximity can lead to relational closeness, but only when participants develop and maintain close and mutually dependent relationships. The establishment of linkages between firms co-located in a region is a key reason for the occurrence of localized knowledge flows and transfers (Li et al., 2013).

Relational or social resources have become central in explaining the behavior and performance of organizations (Nahapiet and Ghoshal, 1998). Particularly, it is said that the structure and nature of the social capital of firms may explain knowledge creation and transmission (Szulanski, 1996; Uzzi, 1997; Hansen, 1999).

It is frequently argued that clusters provide substantial benefits for the firms involved, thanks to the social capital that exists, for instance in terms of flows of knowledge (Uzzi, 1996). In spite of the general consensus on the relevance of social capital, some concerns have yet to be addressed properly. For example, there are different and to some extent contradictory views on the convenience of being in a dense and strong-tie network. Thus, critical voices can be heard arguing that networks also have negative 
effects, such as redundancy and obsolescence of the transmitted knowledge (Glasmeier, 1991; Grabher, 1993).

Redundancy, as a result of dense and strong-tie networks, has already been analyzed in previous literature (Uzzi, 1997; Gargiulo and Benassi, 2000). Although knowledge redundancies have been considered essential to socially build networks (Jenssen and Greve, 2002), in the context of our research, redundancies are viewed as a waste or duplication of knowledge. In fact, we consider Grabher (1993) to be a reference in this respect, since that work is where the process of lock-in of a region was first described. In consequence, redundancy is useless for firms and generates inefficiencies because ties are costly to maintain and also create barriers to obtaining new and exclusive knowledge (Burt, 1992a).

Considering the arguments above, an interesting research question arises. How can firms avoid the wasteful redundancy of ties derived from territorial clusters? Specifically, we have addressed the research question in the context of the effect of the dimensions of social capital, which as far as we know, is a novel development. Particularly, we expect that structural dispersion should be mediator between strength of the ties and redundancy. We do a quantitative study on the Spanish ceramic tile industry to analyze the mediator effect of structural dispersion. We propose that firms embedded in strong-tie networks generate redundant knowledge flows. Additionally, embedded locally-focus firms are more isolated from other networks or other knowledge resources. However, we argue that they may use structural dispersion or weak ties to mediate and overcome this limitation. In other words, firms in clusters can avoid redundancy by combining local intense relations with disperse contacts.

In spite of the great amount of research on social capital, only a handful of studies have focused on the integration between both types of networks - strong-tie and weak-tie - 
between organizations. A contingent view of the effects of social capital (Rowley et al., 2000) states that each characterization of social capital is suitable for different strategic purposes. It depends on the intended strategy pursued by firms in each case. Connections with unconnected actors, or structural dispersion, are suitable for exploring new, exclusive knowledge. In contrast, a dense or strong-tie structure provides exchanges of high-quality tacit knowledge that are suitable for exploiting activities (Capaldo, 2007).

The potential contribution of this study runs parallel to several recent research works, in which the authors have argued against the simplistic association between knowledge and proximity inside the cluster. Those authors have also argued in favor of distinguishing different knowledge needs, from closer relations, or alternatively looking for novel knowledge from more distant sources (Bathelt et al., 2004; Molina-Morales and Martínez-Fernandez, 2009). In this context avoiding unwanted or undesirable knowledge can be a relevant question. To properly address to this question can result in a better understanding of how to overcome potential negative consequences of redundancy can be provided.

This paper has been structured as follows. Firstly, we explain our theoretical framework and hypotheses. Secondly, we describe our methods and the empirical study conducted on one Spanish industrial cluster. Our empirical study was developed drawing on the Spanish ceramic tile industrial cluster in order to test the potential association between social capital dimensions and redundancy. Finally, our findings and possible implications are discussed.

\section{THEORETICAL FRAMEWORK}

\section{The dimensions of social capital}


In order to analyze social capital properly, some conceptual distinctions are required. The first refers to the relational dimension of social capital. Nahapiet and Ghoshal (1998) defined the relational dimension as related to the nature of the ties that are established inside a social network. Strength is the most important attribute of this relational dimension. According to Granovetter (1973), the strength of the ties is defined as the degree of emotional intensity, frequency in relations, as well as the range of types of relations they include (Seibert et al., 2001).

Some advantages for organizations are associated with strong ties. Previous literature reveals that the strength of a tie is associated with higher levels of trust between organizations (Krackhardt, 1992). Learning, particularly that involving difficult-totransfer knowledge, is aided by intensive and repeated interactions. Moreover, trust increases the disposition to openly share information and facilitate forms of interactions between organizations that provide tacit knowledge exchanges (Szulanski, 1996). Thus, when an organization has strong ties with other actors, the process of transferring knowledge becomes more efficient, due to the fact that the focal organization knows the other organization and easily finds valuable information (Gulati et al., 2000). Finally, when ties between organizations are strong, they can agree to help each other in joint problem-solving (Uzzi, 1997). These strong-tie networks allow the transmission of tacit knowledge and high quality information, which is far more difficult to transmit in other contexts (Seibert et al., 2001).

Social capital also presents a second dimension, the structural one. According to Nahapiet and Ghoshal (1998), this structural dimension refers to the whole network, rather than individual ties, as was the case of the relational dimension. Density is the main attribute of the structure of the network, which indicates the degree to which a network is interconnected. Social interactions are manifestations of the structural 
dimension of social capital (Sparrowe et al., 2001). Among the fundamental explanatory tenets of the social network perspective is the idea that the structure of social interactions enhances or constrains access to valued resources (Ibarra, 1993). Resource exchange through informal networks includes work-related resources, such as task advice and strategic information, but informal networks also transmit social identity (norms) and social support (Podolny and Baron, 1997). Social interaction relationships, often established for other purposes, constitute information channels that reduce the amount of time and investment required to gather information.

The literature reveals positive effects of social interactions for organizations. In fact they may facilitate learning processes since interactions provide close, intensive information exchange (Yli-Renko et al., 2001) as well as the creation and diffusion of innovation (Lane and Lubatkin, 1998; Tsai and Ghoshal, 1998; or more recently Molina-Morales and Martínez-Fernandez, 2010).

Similarly to what happens with strong ties, a dense structure can generate negative effects. Following the approach of Burt (1992b; 1995), a dense structure limits new and exclusive knowledge resources, and contacts may provide the same information. In contrast, firms may also benefit from sparse networks. Few partners know one another (many indirect ties) in sparse networks, which provides an opportunity for the organization to obtain diverse resources and perspectives.

\section{Industrial cluster as a territorial network}

Industrial clusters can be understood as a network of inter-organizational relationships between different actors, such as customers, competitors, suppliers, support organizations, and local institutions and others (Piore, 1990). Prior research has explained how industrial clusters represent local configurations that are high in social 
capital, since they are characterized by mutual trust, co-operation, and entrepreneurial spirit, as well as a multitude of small local firms (as opposed to what happens in large firms) with complementary specialized competencies (Dakhli and De Clerq, 2004). Moreover, trust can be better built through repeated interactions and personal contacts, and these contacts are improved because of geographical proximity (Gulati, 1995).

We have used the network as a metaphor to explain the relational characteristics of clusters. Some previous literature has supported the conciliation of cluster and network. A cluster is identified as a network within a production context in a geographically defined area (Boschma and Ter Wal, 2007; Parrilli and Sacchetti, 2008). Thanks to geographical proximity, both common learning and knowledge flows between different actors become frequent phenomena. Thus, the idea of networks within spaces as vehicles of knowledge transfers and diffusion greatly overlap (Boschma and Ter Wal, 2007). Additionally, the network of relationships among firms is typically characterized as a web of dense and overlapping ties which rapidly diffuses knowledge.

Moreover, we suggest that in clusters members are likely to occupy similar positions within a larger social structure and share similar patterns of relationships to other social actors. Firms in clusters are exposed to repeated and frequent relationships with the same actors, in a relatively close network. In fact, interdependency is one of the characteristic features of cluster firms and entities. Actors that are interdependent compete with each other to obtain similar resources and dispose of similar goods and services (Galaskiewicz, 1985).

However, knowledge transfers and access to information vary greatly among firms within clusters (Giuliani and Bell, 2005). Individual firms develop network ties with unique and differentiated structural and relational characteristics. Such variations in firm-specific network characteristics might result in differential access to information, 
resources, and consequent performance differences that are manifested among firms within a cluster (Storper, 1997).

Moreover, horizontally related firms have access to similar types of information because of common structural linkages through trade associations (Vives, 1990), industry-based norms and procedures (Thomas and Soldow, 1988), networks of informal know-how trading (Von Hippel, 1987), and membership in a common technological community (Powell et al., 1996).

In conclusion, an industrial cluster can be viewed as a dense and strong-tie social network where there are close interactions between firms. As a consequence, inside the cluster, knowledge resources flow rapidly, thus reducing search costs (Maskell, 2001). Furthermore, the dynamics of knowledge exploitation are different to those produced in other contexts, which facilitates the learning process and generates beneficial effects for the all the firms in a group. However, these circumstances can generate redundant knowledge due to the similarity in relationships and the resources exchanged. This situation can be negative for firms, as shown by McEvily and Zaheer (1999), who compared the inter-firm information networks of firms in geographical clusters and found that those networks with greater redundancy tend to acquire fewer competitive capabilities.

\section{Knowledge redundancy}

The general meaning of the notion of redundancy can be explained as follows: a person's ego network has redundancy to the extent that his or her contacts are also connected to each other. Following Burt (1992b, 1995) and Krackhardt (1992), among others, we understand redundancy as the degree of overlap in the knowledge bases of two or more social actors. We agree in considering that the meaning of redundancy is not necessarily negative. In fact, some authors have used the notion as a necessary and 
convenient requisite for knowledge resource exchanges to take place (Gargiulo and Benassi, 2000). Moreover, from some perspectives, redundancy is important for the resilience of a network, which is particularly important in some circumstances, such as the case of damage of certain nodes (for instance, a business going out of business). However, firms may also be restrained by redundancy and benefit from sparse networks. Few partners know one another (many indirect ties) in sparse networks, and this provides an opportunity for the organization to obtain diverse resources and perspectives. In consequence, dissimilar resources are more than likely held in less dense networks (Granovetter, 1973; Burt, 2003).

In conclusion, and as argued by Jenssen and Greve (2002), the nature of the effects of redundancy is a controversial issue. In our view, although a certain level of redundancy can be helpful, after a saturation point it becomes negative. Hence, redundancies can be viewed as a waste or duplication of knowledge. Redundancy as overlapping ties is a result of sharing similar positions in a network and consequently firms or social actors are exposed to similar types of information and knowledge. As Adger (2003) notes, only when social or network capital encourages diversity and experimentation will resilience be increased. In particular, dense networks and strong ties are characterized as providing a high degree of redundant knowledge among actors. These networks are also motivated by emotional closeness (Granovetter, 1973), giving rise to island-like cliques (Frenzen and Nakamoto, 1993). This network literature indicates that knowledge redundancy is typically higher among actors that occupy similar social positions (Granovetter, 1973). This contrasts with what happens in disperse networks with weak ties, where diffuse non-redundant bridges link cliques together. Organizations may benefit from belonging to disperse or sparse structures. In these cases, actors rarely know one another, which often results in diverse resources and perspectives. 
If a cluster becomes a very close network, the actors' capacity to respond to new external opportunities and developments is limited (Boschma, 2005). Over-density or over-intensity in the cluster relationships can generate spatial block-in situations, which are detrimental for learning interactions and ultimately for innovation. A close network might even isolate firms from external and profitable sources of knowledge and information (Stuart and Sorenson, 2003) through a lock-in effect (Bathelt et al., 2004). To avoid such spatial lock-in, firms might pursue distant relationships that provide access to the outside world (Hendry et al., 2000).

The idea is that the effect of redundancy (explained in terms of strong ties) is contingent to the stage of the cycle of the cluster (Martin and Sunley, 2006). The strong ties that were previously a source of cumulative economic success become a source of weakness. Grabher (1993) distinguishes between functional lock-in (based on hierarchical firm relations), cognitive lock-in (consisting in a common world view), and political lock-in (a thick and dense institutional structure that hampers restructuring see also Glasmeier, 1991), all of which contributed to negative lock-in. Grabher (1993) defined these obstacles as three kinds of lock-ins, which together can be referred to as regional lock-ins. Focusing on the functional lock-in it refers to hierarchical, close interfirm relationships, particularly between large enterprises and small and medium-sized suppliers, which may eliminate the need for suppliers to develop critical boundaryspanning functions, such as research and development, and marketing.

Diversity of local industries, technologies, and organizations promotes constant innovation and economic reconfiguration, thereby avoiding complete adaptation and lock-in to a fixed structure (Martin and Sunley, 2006). Examples of declining clusters illustrate that the economic advantages that stem from cluster dynamics are not permanent (Hassink, 2010). In fact, the decline of clusters seems to be caused by factors 
that were advantages in the past (Martin and Sunley, 2006). Furthermore, there are several examples of clusters in declining industries that enter new growth phases by going into new fields or integrating new technologies (Grabher, 1993).

The evolutionary perspective contributes to thinking about the relationship between specialization versus diversification, and regional economic growth and stability (Frenken et al., 2007; Martin and Sunley, 2006). On the one hand, variety is seen as a source of regional knowledge spillovers, measured by related variety within sectors. On the other hand, in the case of unrelated variety, variety is seen as a portfolio protecting a region from external shocks. According to Martin and Sunley (2006: 421) "there is a trade-off between specialization and a short-lived burst of fast regional growth on the one hand, and diversity and continual regional adaptability on the other".

Some studies have discussed the life cycle of clusters and the drivers affecting their creation and development. For instance, Belussi and Sedita (2009) highlighted the path dependency in a cluster's evolutionary trends. On the one hand, as Martin and Sunley (2006) argued, the initial phases of the cluster development become established around an expanding industry or set of interrelated industries that stimulate and benefit from emergent external economies, but in many cases as their lead industries and technologies mature, they eventually tend to lose their former growth dynamics and enter a phase of "negative lock-in" and relative economic decline. In this case, the regional economy becomes stuck in established practices and ideas, and networks of interrelatedness and embeddedness that no longer yield increasing returns, and may even induce negative externalities. On the other hand, according to Menzel and Fornahl (2009), cluster dynamics are based on two key processes: the first is that the emergence, growth, decline, and renewal of the cluster depend on the technological heterogeneity of firms; and the second is that firms have a larger relative absorptive capacity, when they 
are in the same location, and thus especially localized learning changes heterogeneity. In fact, it leads to technological convergence when learning takes place within the cluster, and technological divergence when learning takes place outside the cluster, yet in the same region. We agree with Hervas-Oliver and Albors-Garrigos (2011) in considering that there are temporary technological gatekeepers across cluster life cycles which assume the (temporary) role of leaders when it is a question of bringing in disruptive knowledge.

\section{HYPOTHESES}

\section{The strength of the ties and redundancy}

Generally it has been accepted by authors that under certain conditions strength and abundant ties can negatively affect knowledge creation (McFadyen and Cannella, 2004). Strong ties rarely provide new information or knowledge to be used with a certain degree of exclusivity (Burt, 1992a). Multiplex ties help firms gain access to new information, speed up the transfer of knowledge through the cluster, and increase the firms' access to relevant knowledge sources (Uzzi, 1997). In accordance with Granovetter (1973), we suggest that weak ties on the periphery of a network are especially important for the diffusion of breakthrough innovations, which would otherwise be slowed down by strong ties in the network core. A network that is too closed reduces the flow of new knowledge into the network, because the knowledge of the network is not likely to be new and diverse. We can therefore conclude that in an open network structure the benefits accrue to the bridging firm (Burt, 1992a; Kogut, 2000).

Since actors pay little attention to the attributes of partners, they indiscriminately receive a lot of resources, which can rapidly become redundant and obsolete. More 
importantly, this can limit the search horizon to their primary network. On the other hand, strong-tie networks build barriers that exclude new members. As Rowley et al. (2000) argued, up to a certain point the ties established by organizations are substitutes for others, and so it would be better for a firm to combine different ties with external actors instead of dedicating all its time and efforts to strong ties. In fact, maintaining strong ties is far more costly than maintaining weak ones, since they require frequent visits and meetings with people from the other organizations (Hansen, 1999). The lack of external linkages as a consequence of the focus on strong ties is particularly critical when facing significant external environmental changes, since they cannot obtain the capacities or knowledge necessary to compete in the new environment (Pouder and St. John, 1996).

To sum up, the frequency and intensity of contacts between actors that characterize strong ties undoubtedly generate some negative impacts due to the existence of repetitive informational and knowledge resources, and the scarcity of new and exclusive resources. So, in spite of potential benefits, the strength of ties can be expected to be associated with redundancy in knowledge resources.

Hypothesis 1: The strength of ties will be positively associated with the redundant knowledge flows of a clustered firm.

\section{The strength of the ties and structural dispersion}

In order to analyze the mediator effect of the structural dispersion on the relation between strength of ties and knowledge redundant ties a significant association between structural dispersion and strength of ties is required. Moreover, we found enough support in previous research to motivate it. The strength of ties and the density of networks represent the structural and relational dimensions of the social capital of the 
firm, and these two dimensions may influence each other. Thus, the structural dimension may stimulate the relational dimension of social capital. Previous studies have suggested that trusting relationships evolve from social interactions (Gulati, 1995). In fact Tsai and Ghoshal (1998) found a significant association between them in the case of a network of units.

Social capital, however, comes at a cost. As Nahapiet and Ghoshal (1998) pointed out, interpersonal networks can, over time, produce strong norms and mutual identification among network members, thus limiting openness to new information and diverse views. More important interpersonal relationships take time and effort to create and maintain (McFadyen and Cannella, 2004). Strong ties are costly to maintain, since they require energy and attention that involve costs associated with sustaining relationships and preserving slack resources (Leana and Van Buren III, 1999). The members of an organization need to spend time cultivating relationships, and this often involves frequent visits and meetings with other firms, and processing their incoming knowledge from direct contacts. Because of these costs, firms can rarely afford to maintain relations with many other firms, let alone maintain strong ties.

Close social interactions involve both the costs associated with maintaining ongoing relationships, and the norms and costs associated with maintaining slack resources. For instance, an actor (firm) with strong ties with other actors in the network may be complacent about what it has already achieved, and this in turn may cause it to overlook new knowledge that is beyond its current network.

It can be argued that those entities which are not strongly tied to others present fewer restrictions from the organizational system they belong to, and are less exposed to penalties arising from being strongly committed within the network (Weick, 1976). 
A tradeoff can be expected between the strength of the ties and the structural dispersion, and so they are negatively associated. In conclusion, the development of strong ties is costly in terms of resources and time, and in consequence firms can be expected to reduce the contacts with diversified and external actors.

In consequence, clustered firms with strong ties can be expected to have fewer connections with other businesses or geographical locations.

Hypothesis 2: The strength of ties of a clustered firm will be negatively associated with structural dispersion in ties.

\section{Structural dispersion and redundancy}

A firm might be better off establishing other ties to non-redundant actors rather than investing the time and resources required to form and maintain strong ties (Lane and Lubatkin, 1998). In consequence, time and effort invested in social interactions may not be cost-efficient in certain situations or at certain levels (Adler and Kwon, 2002). The dysfunctional effect of the structural dimension arises when firms get locked into their current networks, thus inhibiting their flexibility in creating new ties. In particular, such networks could have an adverse effect on a firm when the environment changes, as they may not have the capabilities or the knowledge necessary to compete in the new environment (Pouder and St. John, 1996). In contrast, when an actor diversifies its contacts and relationships, by developing ties with actors belonging to distant and unconnected contexts, we can expect the generation of wasteful redundant knowledge to be avoided to a certain extent.

As a consequence, structural dispersion can be viewed as a positive characterization in order to avoid the negative consequences of closeness. Accordingly, we predict a 
negative relationship between structural dispersion and redundancy in knowledge resources. This argumentation is formulated as follows:

Hypothesis 3: Structural dispersion in the ties of a clustered firm will be negatively associated with redundant knowledge flows.

\section{Mediator effect of structural dispersion on strong ties}

As Tsai and Ghoshal (1998) suggested, there are undoubtedly connections among the social capital dimensions. The argument is based on the idea that in disperse structures actors' bridging ties can "compensate" for the limitations of strong ties, and thus gain new and exclusive information and knowledge resources, which in turn reduces the undesirable redundancies.

The arguments of structural dispersion assume that an information broker adds significant value above and beyond the costs associated with this position. The power benefits of social capital may, in some cases, trade off its information benefits (Adler and Kwon, 2002). We expect information brokers to be more valuable in dense networks, because they are exposed to a wide variety of solutions to organizational challenges. Based on broad experience gained from observing others who have dealt with similar problems, dispersed actors compile and disseminate summaries about capabilities and routines. Indeed, organizations gain access to the sources of information and resources of the other actors, which in turn enables firms to acquire new innovation capabilities (McEvily and Zaheer, 1999). As a result of bridging many diverse external circles and internal cluster networks, they can explore and transfer new exclusive knowledge and opportunities that are continually refined because of internal redundancy, proximity, and transactional intensity. They facilitate the acquisition of 
competitive capabilities by compiling and disseminating knowledge, and by reducing search costs.

We consider structural dispersion to be a basic explanatory factor that avoids the effects of strong ties on knowledge redundancy, and strong ties are understood to have an indirect effect on knowledge redundancy through the development of structural dispersion. In line with the above arguments, the following hypothesis is formulated:

Hypothesis 4: Structural dispersion mediates in the association between strong ties and redundant knowledge flows.

Figure 1 shows the theoretical model and proposed hypotheses.

Figure 1. Theoretical model and proposed hypotheses

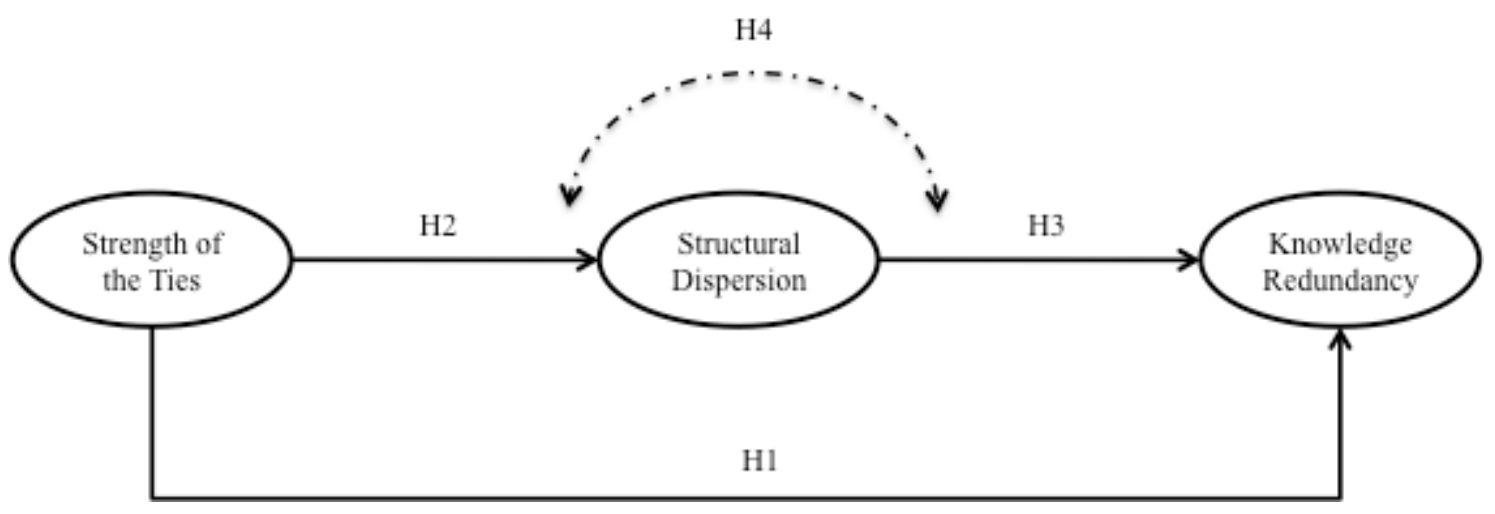

\section{EMPIRICAL STUDY}

\section{Research setting. Description and recent evolution}

The empirical study was conducted within the context of the Spanish ceramic tile industry, situated in the province of Castellón within the Valencian Community in Spain. Known for being a traditional industry, ceramic tile production has emerged as a dynamic and fairly knowledge-intensive activity (Molina-Morales, 2002). The cluster production includes wall and floor tiles, decorative tiles, glazes and frits, machinery and equipment, and other related activities. Together with the firms, there is also a set of 
local institutions and supporting organizations that offer support and services to the whole cluster. These institutions include the local university, research institutes, policy agents, and trade associations, among others. The cluster's success has been achieved thanks to this knowledge-intensive auxiliary industry. The prominent role of the suppliers' linkages with the ceramic tile producers is well known in the Castellon cluster, and constitutes a core advantage at the cluster level. This area (with a radius of no more than 20 kilometers) accounts for roughly $90 \%$ of the total Spanish ceramic tile production. Spain is ranked second in Europe and third after China and Italy in world production. According to $\mathrm{ASCER}^{1}$ (the Spanish Ceramic Tile Trade Association), the main activity production of the cluster in 2009 added up to 350 million square meters, with a turnover of 2,591 million Euros in total sales, $65 \%$ of which was for export, and the sector directly employed around 20,000 workers.

Previous research (Utili et al., 1983; Benton, 1992) has already identified and analyzed the Spanish ceramic tile industry as a district and a cluster. Moreover, most authors include the Spanish case within the Italian model owing to the similarities in their origin and evolution. More recently Boix (2009) clearly identified this ceramic tile agglomeration as a case of Marshallian-type industrial cluster (district). Even Porter (1990) mentioned the existence of this Spanish ceramic tile concentration when describing international competitors of the Italian ceramic tile case. Finally, MolinaMorales (2002) offered a comprehensive description of the whole process of creation of knowledge and innovation in this cluster.

Table 1. Spanish ceramic tile cluster description

\section{Description of the Ceramic Tile Cluster}

\footnotetext{
${ }^{1}$ ASCER (Asociación Española de Fabricantes de Azulejos). This trade association was created in order to support and defend ceramic tile manufacturers. Nowadays it is the main representative association of this industry.
} 


\begin{tabular}{cc}
\hline Characteristics of the company & Number of companies \\
\hline Size (number of employees) & $20(13.42 \%)$ \\
Small (1-19) & $83(55.03 \%)$ \\
Medium (20-99) & $47(31.54 \%)$ \\
Large ( $\geq 100)$ & \\
\hline Annual turnover (million Euros) & $32(21.48 \%)$ \\
Low ( $\leq 5)$ & $25(16.78 \%)$ \\
Medium $(>5,<9)$ & $92(61.74 \%)$ \\
High ( $\geq 10)$ & \\
Main activity & $74(49.66 \%)$ \\
End product firms & $21(14.09 \%)$ \\
Glazes and frits & $31(20.81 \%)$ \\
Machinery and equipment & $14(9.40 \%)$ \\
Special and decorative pieces & $5(3.36 \%)$ \\
Atomized clay & $4(2.68 \%)$ \\
Ceramic additives &
\end{tabular}

\section{Sample collection and data sources}

To define our population of firms, we used the list of ASCER members. Complementary data was obtained from the SABI database ${ }^{2}$, which also allowed us to control some of the questionnaire answers.

Before distributing the questionnaire, we ran a pilot questionnaire with five selected respondents whom we considered to be representative of the whole sample. We use the 2009 listing of membership of the ASCER association. The final firm population consisted of 149 final product firms (Table 1). The fieldwork was carried out in the period from July to October 2009, and the responses were obtained through personal interviews. We collected 92 completed questionnaires (62\% response rate). The interviews were addressed to top managers, CEO (32.6\%) or other members of the management team (67.4\%), since they have a general and complete perspective of the

\footnotetext{
${ }^{2}$ SABI is a directory of Spanish and Portuguese companies that collects both general information and financial data.
} 
company and also they probably have a direct relationship with the main contacts of the company.

The $62 \%$ response rate can therefore be considered highly satisfactory. This rate reduced the risk of bias deriving from missing cases to the minimum expression. Moreover, the final sample presented a balanced, representative distribution. Student's $t$ test was used to check for possible bias between sample and population. We can conclude that there is no bias between sample and population (Table 2).

Table 2. Student's $\boldsymbol{t}$ for mean comparison (Sample and Population)

\begin{tabular}{ccccc}
\hline Variables & $\begin{array}{c}\text { Value of } \\
\text { the test }\end{array}$ & $\mathbf{t}$ & $\begin{array}{c}\text { Sig. } \\
\text { (bilateral) }\end{array}$ & $\begin{array}{c}\text { Mean } \\
\text { differences }\end{array}$ \\
\hline Number of employees & 100 & 1.111 & .269 & 15.493 \\
Total revenues & $16,536,036$ & -.143 & .887 & $-358,932$ \\
Age & 25 & -.063 & .950 & -.130 \\
Company assets & $24,222,340$ & -1.285 & .203 & $-3,240,990.9$ \\
\hline
\end{tabular}

\section{Measurement Variables}

In this paper our study was carried out using three basic variables: knowledge redundancy, strength of the ties, and structural dispersion. In doing this, previous research was reviewed to generate measuring procedures. To some extent we have followed the same approach used in some related papers measuring social capital, among others, Molina-Morales and Martínez-Fernández (2010). Obviously, it had to be adapted to the particular context of our empirical setting and we have specified the references used in each indicator (see Appendix 1 for a description of variables).

\section{Dependent variable}

Knowledge Redundancy: following Staber (2001), we considered Knowledge Redundancy as the degree of similarity in the exchanges between actors. Similarity can 
be captured when the content of the relationships are similar and duplicate knowledge is produced. To measure knowledge redundancy, a seven-point scale with three items is used. The degree to which knowledge exchanges are new or provide an original piece of information is assessed (McEvily and Zaheer, 1999). Additionally, respondents are asked about the degree to which actors in the network know each other, since a closed network is a complementary indicator of knowledge redundancy (McEvily and Zaheer, 1999).

\section{Independent variables}

Strength of the Ties: the strength of the ties was measured using the dimensions put forward by Granovetter (1973) to characterize such ties, namely frequency, emotional intensity, intimacy, mutual confidence, and mutual services ties. Previous research was reviewed and these concepts were adapted. Firstly, McEvily and Zaheer (1999) proposed the concept of "Infrequency of interaction". The authors asked about the interaction with advisors in terms of the average number of conversations per month. Secondly, intimacy and mutual confidence are considered to be the intensity in a cooperation relationship (Brown and Konrad, 2001). Rowley et al. (2000) considered that a focal actor whose direct partners are densely connected to one another will need to cooperate in order to avoid negative sanctions from the tightly linked collective. Thirdly, Yli-Renko et al. (2001) captured intensity in social interactions; they measured social interaction reflecting the extent to which the relationship is characterized by personal and social ties. Finally, previous job experience in other cluster firms by executives, engineers, and employees is regarded as the stock of market and technology knowledge, which is tacit and specific to the cluster context. We adapted the idea of Tsai and Ghoshal (1998) about members of the unit that have previously worked in other companies. In sum, a seven-point scale with four items was proposed. 
Structural dispersion: this variable measures the degree of connectivity outside the network. Non-redundant contacts offer information benefits that are additive rather than redundant. We assume that if the ego-network of a company has cluster external actors, the structural dimension of this network will be more disperse than other companies in the cluster with fewer external links. Structural holes are the gaps between nonredundant contacts (Burt, 1992b). Following Burt (1992b), the structural holes argument defines social capital in terms of the information and control advantages of being the broker in relations between people who are otherwise disconnected in the social structure. Particularly, in McEvily and Zaheer (1999) the physical distance of the actors was used as an indicator of the existence of bridging ties. Thus, we asked about the dependence of the firm with respect to other businesses or geographical circles in obtaining relevant resources and spending time cultivating ties from other geographical circles. According to the notion of the industrial cluster, it can be assumed that the contacts outside it are under the conditions of the structural holes. Thus, based on McEvily and Zaheer (1999) and the argument above, we proposed a seven-point scale with three items.

Control variables. Size: size is usually employed as a control variable. Firms of a larger size can be expected to invest more resources in obtaining new knowledge sources. The number of employees, age unit sales, and assets have been used as variables.

\section{RESULTS}

Firstly, we generated descriptive statistics, including Mean, Standard Deviation, Cronbach's Alpha, and Pearson's correlation (Table 3). Secondly, we carried out a linear regression analysis to contrast the hypotheses (Table 4). All the models were computed using the statistics software SPSS version 16.0. 
Although no consensus exists, it is considered that Cronbach's Alpha values lower than .60 indicate a non-satisfactory reliability. Therefore, in our case (Table 3), scales have a satisfactory value for internal consistency. Each set of items of a variable was then grouped in a factor to be used in the regression analysis. In this case the average of all the sample items was computed.

Table 3. Descriptive statistics, Cronbach's Alpha and Pearson correlations

\begin{tabular}{|c|c|c|c|c|c|c|c|c|c|c|}
\hline Variables & Mean & S.D. & $\alpha$ & 1 & 2 & 3 & 4 & 5 & 6 & 7 \\
\hline (1) Knowledge Redundancy & 5.750 & .775 & .707 & 1 & & & & & & \\
\hline (2) Strength of the Ties & 4.126 & .905 & .673 & $.365 *$ & 1 & & & & & \\
\hline (3) Structural Dispersion & 1.581 & .778 & .666 & $-.526 * *$ & $-.475^{*}$ & 1 & & & & \\
\hline (4) Log-revenues & 6.982 & .573 & - & .059 & .073 & -.079 & 1 & & & \\
\hline (5) Employees & 111 & 130 & - & .054 & .064 & -.152 & $.414^{* *}$ & 1 & & \\
\hline (6) Age & 24 & 19 & - & -.089 & -.072 & .074 & -.047 & $.338^{*}$ & 1 & \\
\hline (7) Log-assets & 5.91 & 2.68 & - & -.095 & .015 & -.027 & .053 & .170 & .106 & 1 \\
\hline
\end{tabular}

$\mathrm{N}=92$; Pearson's correlation is significant at levels: $\mathrm{p}<.01 * * ; \mathrm{p}<.05^{*}$

The mediation model was tested following Kenny et al. (1998). Thus, a variable (M) mediates the association between variable (X), as the antecedent, and variable (Y), as the outcome, only if the following conditions are fulfilled: (1) $\mathrm{X}$ is significantly associated to $\mathrm{Y}$; (2) $\mathrm{X}$ is significantly associated to $\mathrm{M}$; (3) After controlling for $\mathrm{X}, \mathrm{M}$ remains significantly associated to $\mathrm{Y}$; and (4) After controlling for $\mathrm{M}$, the $\mathrm{X}-\mathrm{Y}$ association is zero. To test mediation effect, various regression equation analyses were performed, as shown in Table 4 and illustrated in Figure 1.

Table 4. Results of multiple hierarchical regression analyses for the relationship between the Strength of Ties, Structural Dispersion, and Knowledge Redundancy

\begin{tabular}{cccc}
\hline Knowledge & Structural \\
Redundancy & Kispersion & Knowledge & Knowledge \\
Redundancy & Redundancy \\
Model & Model & Model & Model \\
(condition) 1 & (condition) 2 & (condition) 3 & (condition) 4 \\
\hline
\end{tabular}




\begin{tabular}{|c|c|c|c|c|}
\hline Constant & $4.369(1.105)^{* *}$ & $2.940(1.044)^{*}$ & $6.282(.974)^{* *}$ & $5.706(1.048)^{*}$ \\
\hline Strength of the Ties & $.305(.086)^{* *}$ & $-.395(.081)^{* *}$ & & $.125(.088)$ \\
\hline Structural Dispersion & & & $-.524(.092)^{* *}$ & $-.455(.104)^{* *}$ \\
\hline Log-revenues (control) & $.031(.153)$ & $.042(.144)$ & $.058(.140)$ & $.050(.139)$ \\
\hline Employees (control) & $.001(.001)$ & $-.001(.001)$ & $.000(.001)$ & $.000(.001)$ \\
\hline Age (control) & $-.004(.004)$ & $.004(.004)$ & $-.002(.004)$ & $-.002(.004)$ \\
\hline Log-assets (control) & $.000(.000)$ & $.000(.000)$ & $.000(.000)$ & $.000(.000)$ \\
\hline$F$ & $3.113 *$ & $5.713 * *$ & $7.134 * *$ & $6.356^{* *}$ \\
\hline$R^{2}$ & .153 & .249 & .293 & .310 \\
\hline Adjusted $R^{2}$ & .104 & .206 & .252 & .261 \\
\hline
\end{tabular}

Model 1 in Table 4 presents the results of the first regression, in which Knowledge Redundancy was regressed on the Strength of the Ties and the control variables. The results showed a statistically significant relationship between the variables $(\beta=.311$, $p<.001$ ), in support of Hypothesis 1 . Model 2 in Table 4 presents the results of the second regression, in which Structural Dispersion regressed on the Strength of the Ties and the control variables. The results showed a statistically significant (and negative) relationship between the variables $(\beta=-.406, p<.001)$, in support of Hypothesis 2 . Model 3 in Table 4 presents the results of the third regression, in which Knowledge Redundancy was regressed on the Structural Dispersion and the control variables. The results showed a statistically significant (and negative) relationship between the variables $(\beta=-.522, p<.001)$, in support of Hypothesis 3. Finally, Model 4 in Table 4 tested Hypothesis 4, in which regressed Knowledge Redundancy depends on the Strength of the Ties and the mediator Structural Dispersion, as well as the control variables. The effect of the mediator Structural Dispersion on Knowledge Redundancy remained significant $(\beta=-.452, p<.001)$, and the effect of the Strength of the Ties remained non-significant $(\beta=.127, p=$ n.s. $)$, in support of Hypothesis 4 . The results of the mediation model can be seen in Figure 2. 
Figure 2. The relationship between Strength of Ties, Structural Dispersion, and Knowledge Redundancy

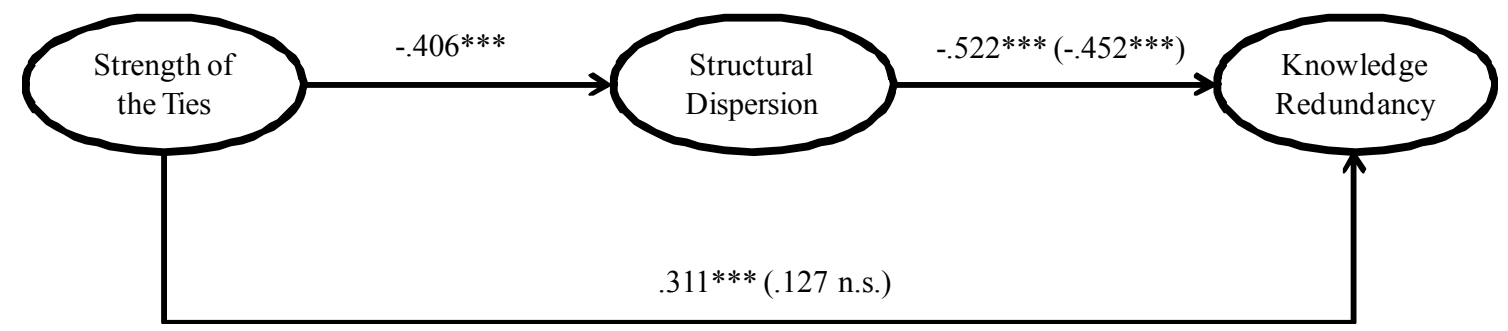

Redundancy refers to the results or consequences of relations, while the construct of strength of the ties refers to the nature of the relation. Both the variables are correlated as expected. We attempt to test the mediator effect of the structural dispersion on the relation between strong ties and redundancy. In our opinion, and this is the possible contribution of the paper, the structural dimension of social capital provides a basic explanatory factor of the capacity of firms to reduce knowledge redundancy in a context of geographical proximity. Therefore, in contrast to the assumption of a direct effect of the strong ties on redundancy, we argue that strong ties only have a significant effect on redundancy when the structure of the network is not considered. In fact, these findings suggest a new way to analyze the dynamics of the networks of locally clustered firms.

\section{DISCUSSION AND CONCLUSIONS}

This work was based on the expected complex relationships between the dimensions of social capital and the generation of wasteful knowledge redundancy. Particularly, we assumed that strong ties were positively associated to redundancy, while structural dispersion was negatively associated with it. On the other hand, the cluster as a particular relational context for firms has been identified as a dense network where firms interact in close, intimate circles to establish strong ties. The network provides firms with a number of advantages associated to the creation of trust and other common 
values, as well high quality information and knowledge (Coleman, 1990; Uzzi, 1996, 1997). In spite of the advantages, this type of network causes wasteful redundant knowledge, as confirmed by our results.

The paper's contribution is in line with those authors who propose a contingent perspective of the effect of social networks on firms (Podolny and Baron, 1997; Rowley et al., 2000; Gargiulo and Benassi, 2000). Hence, a firm would do better to establish a specific combination of strong and structural dispersion according to its strategic purposes. As Andersson et al. (2002) argued, there is a relevant distinction between the advantages in terms of power provided by the brokerage position in a non-redundant-tie network and the advantage of cohesion from being a member of a strong-tie network. In the same vein, Kogut (2000) argued that each type of network (weak- and strong-tie) generates breaks in coordination, although with very different implications. In consequence, an appropriate approach would probably be a contingent approach rather than establishing a hierarchy or postulating a universal preference.

Moreover, our research represents a step forward, since we establish that structural dispersion mediates in the effect between strong ties and redundancy. This means that firms in clusters can avoid knowledge redundancy by combining local intense relations with disperse contacts.

We consider that this research contributes to a better understanding of the mechanisms allowing firms access to new sources of knowledge. Particularly, we have studied the relationships between social capital and knowledge acquisition in the context of the industrial cluster. In fact, our findings allow us to describe a more realistic relationship between the strength of ties and the resulting resources. 
In our opinion, our paper's findings also contribute to the current discussion on the future of industrial clusters. Although local sources of competitiveness are still crucial, clusters must look to the external context, that is, towards international markets where they can place their products, while also drawing on international sources of knowledge and technology. Furthermore, these ties linking companies both inwards and outwards are mutually reinforced and help them to become more competitive in these international markets (Corò and Grandinetti, 1999; Humphrey and Schmitz, 2002).

Obviously, our paper presents some limitations that we will attempt to address in future research. Firstly, the dynamics of the network structure and how it is created or modified is an interesting subject for future research. Another area of inquiry would refer to how firms' networks evolve in response to external changes. A final question may concern the bias that can result from using only one industry. Thus, we must be cautious about generalizing results and conclusions. A broader analysis is therefore needed to examine how other cases vary.

\section{REFERENCES}

Adler, P. and Kwon, S. (2002) Social capital: prospects for a new concept, Academy of Management Review, 27(1), pp. 17-40.

Adger, W. (2003) Social capital, collective action, and adaptation to climate change, Economic Geography, 79(4), pp. 387-404.

Andersson, U., Forsgren, M. and Holm, U. (2002) The strategic impact of external networks: Subsidiary performance and competence development in the multinational corporation, Strategic Management Journal, 23, pp. 979-996.

Bathelt, H., Malmberg, A. and Maskell, P. (2004) Clusters and Knowledge: Local Buzz, Global Pipelines and the Process of Knowledge Creation, Progress in Human Geography, 28(1), pp. 31-56.

Becattini, G. (1990) The marshallian industrial district as a socio-economic notion in Pyke, F., Becattini, G. and Sengenberger, W. (Eds.) Industrial districts and local economic regeneration (International Institute for Labor Studies, Geneva).

Belussi, F. and Sedita, S. (2009) Life Cycles vs. Multiple Path Dependency in Industrial Districts, European Planning Studies, 17(4), pp. 505-527. 
Benton, L. (1992) The Emergence of the Industrial District in Spain, in: F. Pyke; G. Becattini and W. Sengenberger (Eds.) Industrial Districts and Local Economic Regeneration (Geneva: International Institute for Labor Studies).

Boix R. (2009) The Empirical Evidence of Industrial Districts in Spain, in Becattini G., Bellandi M. and De Propris L. (Eds) A Handbook of Industrial Districts (Edward Elgar, Cheltenham, United Kingdom).

Boschma, R. A. (2005) Proximity and innovation: a critical assessment, Regional Studies 39(1), pp. 1-14.

Boschma, R.A. and Ter Wal, A.L.J. (2007) Knowledge networks and innovative performance in an industrial district: The case of a footwear district in the south of Italy, Industry and Innovation, 14, pp. 177-99.

Brown, D.W. and Konrad, A.M. (2001) Granovetter was right. The importance of weak ties to a contemporary job search, Group \& Organization Management, 26, pp. 434462.

Burt, R.S. (1992a) Social structure of competition, in: N. Nohria \& R.G. Eccles (Eds), Networks and organizations: Structure, form and action (Boston: Harvard Business School Press).

Burt, R.S. (1992b) Structural holes (Cambridge: Harvard University Press).

Burt, R.S. (1995) Structural holes. The social structure of competition (Cambridge: Harvard University Press).

Burt, R.S. (2003) Structural Holes and Good Ideas, American Journal of Sociology, 110(2), pp. 349-399.

Capaldo, A. (2007) Network structure and innovation: the leveraging of a dual network as a distinctive relational capability, Strategic Management Journal, 28, pp. 585-608.

Coleman, J.S. (1990) Foundation of Social Theory (Cambridge: Harvard University Press).

Corò, G. and Grandinetti, R. (1999) Evolutionary patterns of Italian industrial districts, Human Systems Management, 18, pp. 117-129.

Dakhli, M. and De Clercq, D. (2004) Human capital, social capital, and innovation: A multicountry study, Entrepreneurship \& Regional Development, 16, pp. 107-128.

Frenken, K. Van Oort, F.G. and Verburg, T. (2007) Related variety, unrelated variety and regional economic growth. Regional Studies, 41(5), pp. 685-697.

Frenzen, J. and Nakamoto, K. (1993) Structure, Cooperation, and the Flow of Market Information, Journal of Consumer Research, 20, pp. 360-75.

Galaskiewicz, J. (1985) Social organization of an urban grants economy (Orlando: Academic Press).

Gargiulo, M. and Benassi, M. (2000) Trapped in your own net? Network cohesion, structural holes, and the adaptation of social capital, Organization Science, 11, pp. 183196. 
Giuliani, E. and Bell, M. (2005) The micro-determinants of meso-level learning and innovation: evidence from a Chilean wine cluster, Research Policy, 34(1), pp. 47-68.

Glasmeier, A. (1991) Technological Discontinuities and Flexible Production Networks: The Case of Switzerland and the World Watch Industry, Research Policy, 20, pp. 469485.

Grabher, G. (1993) The weakness of strong ties: The lock-in of regional development in the Ruhr area, in: G. Grabher (Ed), The embedded firm: on the socioeconomics of industrial networks (London: Routledge).

Granovetter, M. (1973) The strength of weak ties, American Journal of Sociology, 78, pp. 1360-1380.

Gulati, R. (1995) Social structure and alliance formation patterns: a longitudinal analysis, Administrative Science Quarterly, 40(4), pp. 619-642.

Gulati, R., Nohria, N. and Zaheer, A. (2000) Strategic Networks, Strategic Management Journal, 21, pp. 203-215.

Hansen, M.T. (1999) The search-transfer problem: The role of weak ties in sharing knowledge across organizational subunits, Administrative Science Quarterly, 44, pp. $82-111$.

Hassink, R. (2010) Locked in decline? On the role of regional lock-ins in old industrial areas. In: R. Boschma and R. Martin (Eds), Handbook of Evolutionary Economic Geography (Cheltenham: Edward Elgar).

Hendry C., Brown, J. and DeFillippi, R.J. (2000) Regional Clustering of High Technology-Based Firms: Opto-Electronics in Three Countries, Regional Studies, 34(2), pp.129-144.

Hervas-Oliver, J.L. and Albors-Garrigos, J. (2011) Resources and innovation in lowtech industries: An empirical study of clusters in Spain and Italy, Knowledge transfer and technology diffusion, pp. 35-63.

Humphrey, J. and Schmitz, H. (2002) How does insertion in global value chains affect upgrading in industrial clusters?, Regional Studies, 36, pp. 1017-27.

Ibarra, H. (1993) Network centrality, power and innovation involvement: Determinants of technical and administrative roles, Academy of Management Journal, 36, pp. 471501 .

Jenssen, J.I. and Greve, A. (2002) Does the degree of redundancy in social networks influence the success of business start-ups?, International Journal of Entrepreneurial Behaviour \& Research, 8(5), pp. $254-267$.

Kenny D.A., Kashy, D. and Bolger, N. (1998) Data analysis in social psychology, in: D. Gilbert, S. Fiske \& G. Lindzey (Eds) Handbook of Social Psychology (New York: McGraw-Hill).

Kogut, B. (2000) The Network as Knowledge: Generative Rules and the Emergence of Structure, Strategic Management Journal, 21, pp. 405-425.

Krackhardt, D. (1992) The strength of strong ties: the importance of philos, in: N. Nohria \& R.G. Eccles (Eds) Networks and organizations: Structure, form and action (Boston: Harvard Business School Press). 
Lane, P.J. and Lubatkin, M. (1998) Relative absorptive capacity and interorganizational learning, Strategic Management Journal, 19, pp. 461-477.

Leana, C.R. and Van Buren III, H.J. (1999) Organizational social capital and employment practices, Academy of Management Review, 24, pp. 538-555.

Li, W., Veliyath, R. and Tan, J. (2013) Network Characteristics and Firm Performance: An Examination of the Relationships in the Context of a Cluster, Journal of Small Business Management, 51(1), pp. 1-22.

Lorenzen, M. (2007) Social capital and localised learning: proximity and place in technological and institutional dynamics, Urban Studies, 44(4), pp. 799-817.

Malecki E. (1995) Culture as Mediator of Global and Local Forces, in Van Der Knaap B. and Le Heron R. (Eds) Human Resources and Industrial Spaces: A Perspective on Globalization and Localization, 105-27, (John Wiley \& Sons, Chichester, United Kingdom).

Martin, R. and Sunley, P. (2006) Path dependence and regional economic evolution, Journal of Economic Geography, 6, pp. 395-437.

Maskell, P. (2001) Knowledge creation and diffusion in geographic clusters, International Journal of Innovation Management, 5(2), pp. 213-225.

McEvily, B. and Zaheer, A. (1999) Bridging ties: A source of firm heterogeneity in competitive capabilities, Strategic Management Journal, 20(12), pp. 1133-1156.

McFadyen, M.A. and Cannella, A.A.Jr. (2004) Social capital and knowledge creation: diminishing returns of the number and strength of exchange relationships, Academy of Management Journal, 47, pp. 735-746.

Menzel, M.P. and Fornahl, D. (2010) Cluster life cycles - dimensions and rationales of cluster evolution, Industrial and Corporate Change, 19(1), pp. 205-238.

Molina-Morales, F.X. (2002) Industrial districts and innovation: the case of the Spanish ceramic tiles industry, Entrepreneurship and Regional Development, 14, pp. 211-228.

Molina-Morales, F.X. and Martínez-Fernández, M.T. (2009) Too much love in the neighborhood can hurt: How an excess of intensity and trust in relationships may produce negative effects on firms, Strategic Management Journal, 30, pp. 1013-1023.

Molina-Morales F.X. and Martínez-Fernández, M.T. (2010) Social networks: effects of social capital on firm innovation, Journal of Small Business Management, 48(2), pp. 258-279.

Nahapiet, J. and Ghoshal, S. (1998) Social capital, intellectual capital, and the organizational advantage, Academy of Management Review, 23(2), pp. 242-266.

Parrilli, M.D. and Sacchetti, S. (2008) Linking Learning with Governance in Networks and Clusters: Key Issues for Analysis and Policy, Entrepreneurship and Regional Development, 20(July), pp. 387-408.

Piore, M.J. (1990) Work, labor and action: Work experience in a system of flexible production, in: F. Pyke, G. Becattini \& W. Sengenberger (Eds), Industrial districts and inter-firm cooperation in Italy (Geneva: International Institute for Labor Studies).

Podolny, J.M. and Baron, J.N. (1997) Resources and relationships: Social networks and mobility in your workplace, American Sociology Review, 62, pp. 673-693.

Porter, M.E. (1998) On Competition (Boston: Harvard Business Review Press). 
Porter, M.E. (1990) The competitive advantage of the nations (The Free Press, New York).

Pouder, R. and St. John, C.H. (1996) Hot spots and blind spots: Geographic clusters of firms and innovation, Academy of Management Review, 21(4), pp. 1192-1225.

Powell, W., Koput, K. and Smith-Doerr, L. (1996) Interorganizational Collaboration and the Locus of Innovation: Networks of Learning in Biotechnology, Administrative Science Quarterly, 41, pp. 116-45.

Rowley, T., Behrens, D. and Krackhardt, D. (2000) Redundant governance structures: An analysis of structural and relational embeddedness in the steel and semiconductor industries, Strategic Management Journal, 21, pp. 369-386.

Seibert, S.E., Kraimer, M.L. and Liden, R.C. (2001) A social capital theory of career success, Academy of Management Journal, 44(2), pp. 219-237.

Sorenson, O (2003) Interdependence and Adaptability: Organizational Learning and the Long-term Effect of Integration, Management Science, 49, pp. 446-463.

Sparrowe, R., Liden, R., Wayne, S. and Kraimer, M. (2001) Social networks and the performance of individuals and groups, Academy of Management Journal, 44(2), pp. 316-325.

Staber, U. (2001) The structure of networks in industrial districts, International Journal of Urban and Regional Research, 25(3), pp. 537-552.

Storper M. (1997) The Regional World: Territorial Development in a Global Economy, (The Guilford Press, New York).

Stuart, T. and Sorenson, O. (2003) The geography of opportunity: spatial heterogeneity in founding rates and the performance of biotechnology firms, Research Policy, 32, pp. 229-253.

Szulanski, G. (1996) Exploring internal stickiness: Impediments to the transfer of best practice within the firm, Strategic Management Journal, 17, pp. 27-43.

Tallman, S., Jenkins, M., Henry, N. and Pinch, S. (2004) Knowledge, clusters, and competitive advantage, Academy of Management Review, 29, pp. 258-271.

Thomas, G.P. and Soldow, G.F. (1988) A Rules-Based Approach to Competitive Interaction, Journal of Marketing, 52, pp. 63-74.

Trigilia, C. (2001) Social capital and local development, European Journal of Social Theory, 4(4), pp. 427-442.

Tsai, W. and Ghoshal, S. (1998) Social capital and value creation: The role of intrafirm networks, Academy of Management Journal, 41(4), pp. 464-478.

Utili, G., Sarti, M. and Gobbo, F. (1983) L'industria delle piastrelle di ceramica nel mondo. I principali paese produttori (Modena: Nomisma-Edi).

Uzzi, B. (1996) The sources and consequences of embeddedness for the economic performance of organizations, American Sociological Review, 61, pp. 674-698.

Uzzi, B. (1997) Social structure and competition in interfirm networks. The paradox of embeddeness, Administrative Science Quarterly, 42, pp. 35-67.

Vives, X. (1990) Trade association disclosure rules, incentives to share information and welfare, RAND Journal of Economics, 21, pp. 409-302. 
Von Hippel, E. (1987) Cooperation Between Rivals: Informal Know-How Trading, Research Policy, 16, pp. 291-302.

Weick, K. (1976) Educational organizations as loosely coupled systems, Administrative Science Quarterly, 21, pp. 1-19.

Yli-Renko, H., Autio, E. and Sapienza, J.H. (2001) Social capital, knowledge acquisition, and knowledge exploitation in young technology-based firms, Strategic Management Journal, 22, pp. 587-613. 


\title{
APPENDIX I: EXTRACT OF THE QUESTIONNAIRE'S ITEMS
}

\author{
Knowledge Redundancy (7-point Likert scale)
}

1.1 The content of the knowledge your organization exchanges with individuals and organizations in the ceramic tile cluster was new to the firm or provides a substantial original piece of information versus well-known or widely shared bits of information.

1.2 In general, individuals and organizations with which your organization maintains frequent relationships in your cluster, know each other. You consider them as a close or intimate circle of relationships.

1.3 The contacts of your company has can be characterized by a few groups of similar relationships.

Strength of the Ties (7-point Likert scale)

2.1 Thinking on the most relevant individuals and organizations in your cluster from which your organization receives advice, information or any relevant input for your organization, tell us approximately how many conversations or contacts you have per month (1=daily, 7 =sporadic).

2.2 Your organization cooperates (by sharing goals and common objectives) with individuals and organizations in your cluster.

2.3 In general your organization carries out close social relationships with individuals and organizations located in the ceramic cluster (i.e. you participate in social events, family, business and other celebrations and parties).

2.4 In general, the executives, technicians and employees from your organization have previously worked in other companies belonging to the same cluster.

Structural Dispersion (7-point Likert scale)

3.1 Individuals and organizations from which your organization received advice for decision making and problem-solving belong to diverse business and geographical circles.

3.2 In general, information and knowledge input from individuals and organizations which are located in other and diverse business or geographical locations are more and more relevant for your organization.

3.3 Your company is interested in spending time and resources cultivating ties with firms from other geographical circles.

Control

4.1 Total revenue last year. 